\title{
APOCRINE CARCINOMA OF THE BREAST. CLINICAL, HISTOLOGICAL AND IMMUNOHISTOCHEMICAL FEATURES
}

\author{
Tatyana M. BETOVA ${ }^{1 凶}$, Radoslav G. TRIFONOV ${ }^{2}$, Savelina L. POPOVSKA ${ }^{1}$, Ivan N. IVANOV ${ }^{1}$, \\ Sergey D. KOSTADINOV ${ }^{3}$
}

${ }^{1}$ Department of Pathoanatomy, Medical University - Pleven, Pleven, Bulgaria

${ }^{2}$ Faculty of Medicine, Medical University - Pleven, Pleven, Bulgaria

${ }^{3}$ Department of General Medicine, Forensic Medicine and Deontology, Faculty of Public Health, Medical

University - Pleven, Pleven, Bulgaria

Received 12 Aug 2020, Accepted 20 Sept 2020

https://doi.org/10.31688/ABMU.2020.55.4.21

\begin{abstract}
Introduction. Invasive apocrine carcinoma of the breast is a rare special subtype of mammary carcinoma and accounts for $0.3-1 \%$ of all breast malignancies. It has specific histological, immunohistochemical, and molecular genetic characteristics. The tumour cells have a unique immunohistochemical profile, which is to show Gross Cystic Disease Fluid Protein 15 (GCDFP-15) and androgen receptor (AR) positivity, as well as estrogen (ER), progesterone (PR), and Human Epidermal Growth Factor Receptor 2 (HER2) negativity.
\end{abstract}

Case presentation. We report a case of invasive apocrine carcinoma in a 55-year-old female with a lump in the right breast and no axillary lymphadenopathy. Lumpectomy and sentinel node biopsy were performed. The histological examination and the immunohistochemical profile confirmed the diagnosis of invasive apocrine carcinoma with micrometastasis in sentinel lymph node which, to our knowledge, is the first published case. Due to the involvement of one of the resection lines from high grade apocrine ductal

\section{RÉsumé}

Carcinome apocrine du sein. Caractéristiques cliniques, histologiques et immunohistochimiques

Introduction. Le carcinome apocrine invasif du sein est un sous-type spécial rare de carcinome mammaire et représente $0.3-1 \%$ de toutes les tumeurs malignes du sein. Il possède des caractéristiques génétiques histologiques, immunohistochimiques et moléculaires spécifiques. Les cellules tumorales ont un profil immunohistochimique unique, qui doit montrer la positivité de protéine liquide de la maladie kystique brute 15 (GCDFP-15) et des récepteurs aux androgènes (AR), ainsi que les œstrogènes (ER), la progestérone (PR) et la négativité du récepteur 2 du facteur de croissance épidermique humain (HER2).

Présentation du cas. Nous rapportons un cas de carcinome apocrine invasif chez une femme de 55 ans avec une bosse dans le sein droit et sans lymphadénopathie axillaire. Une lumpectomie et une biopsie du ganglion sentinelle ont été effectuées. L'examen histologique et le profil immunohistochimique ont 
carcinoma in situ (DCIS), the patient underwent right modified radical mastectomy with axillary dissection. Conclusions. This report is a rare specific morphological type of invasive apocrine carcinoma with micrometastasis in sentinel lymph node. The unique immunohistochemical profile, the possibility of an anti-AR therapy, and the favorable prognosis separate it from basal-like triple-negative breast cancers.

Keywords: breast cancer, invasive apocrine carcinoma, pathology, immunohistochemistry.

\author{
Abbreviations: \\ IAC - invasive apocrine carcinoma \\ GCDFP-15 - Gross Cystic Disease Fluid Protein 15 \\ ER - estrogen \\ PR - progesterone
}

HER2 - Human Epidermal Growth Factor Receptor 2

TNBC - triple negative breast cancer

AR - androgen

SLN - sentinel lymph node

DCIS - ductal carcinoma in situ

ICH - immunohistochemistry

H\&E - hematoxylin and eosin

\section{INTRODUCTION}

Invasive apocrine carcinoma (IAC) of the breast is a rare special subtype of mammary carcinoma, as it has specific morphological, immunohistochemical, and molecular genetic characteristics. It was first documented by Krompecher in 1916 . From all invasive types of breast cancer, IAC represents less than $1 \%$ of cases $^{2}$. IAC has unique morphological and immunohistochemical characteristics; it also has the tendency to show expressions of Gross Cystic Disease Fluid Protein 15 (GCDFP-15), estrogen (ER), progesterone (PR) and Human Epidermal Growth Factor Receptor 2 (HER2) negativity. These traits place most of the cases in the category of triple negative breast cancer (TNBC) ${ }^{3,4}$. Between $10-30 \%$ of TNBC cases are characterized by overexpression for androgen (AR) receptor and AR pathway activation, which is typical of apocrine carcinomas ${ }^{4,5}$. This feature underlies the suggested separation of IAC of the breast into the "molecular apocrine group" and facilitates receptor target endocrine therapy ${ }^{6,7}$. We present a case of a woman with triple negative, AR positive IAC with micrometastasis in sentinel lymph node (SLN).

\section{Case presentation}

A 55-year-old woman, with a medical history of rheumatoid arthritis and three years of therapy with confirmé le diagnostic de carcinome apocrine invasif avec micrométastase dans le ganglion lymphatique sentinelle, qui est à notre connaissance le premier cas publié. En raison de l'implication de l'une des lignes de résection d'un carcinome canalaire apocrine de haut grade in situ (CCIS), le patient a subi une mastectomie radicale modifiée à droite avec dissection axillaire.

Conclusions. Ce rapport est un type morphologique spécifique rare de carcinome apocrine invasif avec micrométastase dans le ganglion sentinelle. Le profil immunohistochimique unique, la possibilité d'une thérapie anti-AR et le pronostic favorable le séparent des cancers du sein triple négatifs de type basal.

Mots-clés: cancer du sein, carcinome apocrine invasif, pathologie, immunohistochimie.

Methotrexate Ebewe $15 \mathrm{mg}$ once weekly and nine months of therapy with leflunomide $20 \mathrm{mg}$ once daily, presented with an abnormal finding on screening mammography of the right breast. The patient had history of mastopathic plaque and cyst $(6 \mathrm{~mm})$ of the left breast and no evidence of familial cancer. The physical examination revealed no palpable mass or skin changes of the breast or pain. The mammography showed a new tumour in the upper inner quadrant of the right breast, irregular in shape, with a size of $5 \mathrm{~mm}$, and single microcalcifications, assumed as category 4 according to Breast Imaging-Reporting and Data System (Figure 1). Ultrasonography images of the same breast showed a rounded hypoechoic lesion with uneven outlines, about $5-6 \mathrm{~mm}$ in size, in the upper inner quadrant (Figure 2).

The preoperative laboratory tests showed elevated CRP $(6.26 \mathrm{mg} / \mathrm{dL}$, reference range $<5 \mathrm{mg}$ / $\mathrm{dL})$ and fibrinogen $(452 \mathrm{mg} / \mathrm{dL}, 200-400 \mathrm{mg} / \mathrm{dL})$, and normal erythrocyte sedimentation rate (ESR) $(17 \mathrm{~mm} / \mathrm{h}, 0-25 \mathrm{~mm} / \mathrm{h})$. The tumour marker CA15-3 $(21.37 \mathrm{U} / \mathrm{mL})$ was in the reference range (CA15-3 $<35.0 \mathrm{U} / \mathrm{mL}$ ). Lumpectomy of the suspicious lesion of the right breast and sentinel node biopsy were performed. The histopathological report described an invasive tumour with a diameter of $5 \mathrm{~mm}$, microscopically composed of atypical polygonal cells, with abundant granular and eosinophilic cytoplasm (periodic acid-Schiff positivity), oval centrally located nuclei 


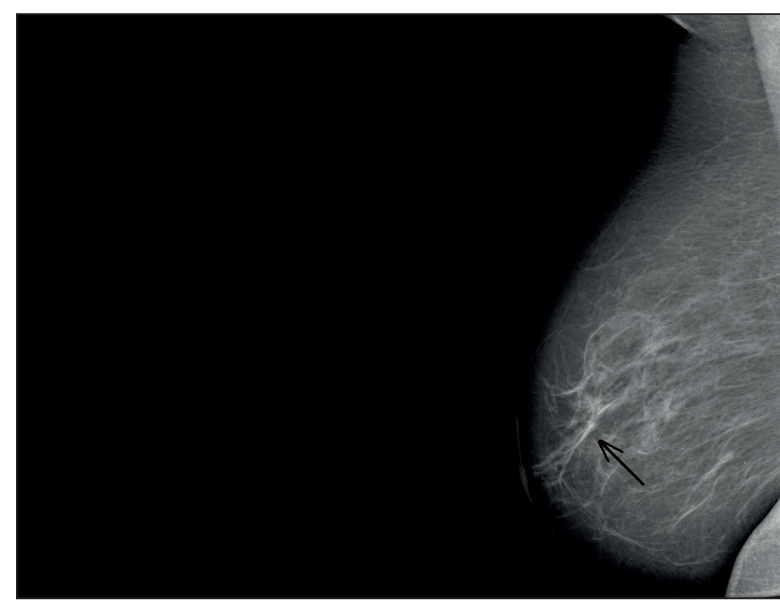

Figure 1. Mammography revealing an isodense lesion (arrow) in the upper inner quadrant of the right breast.

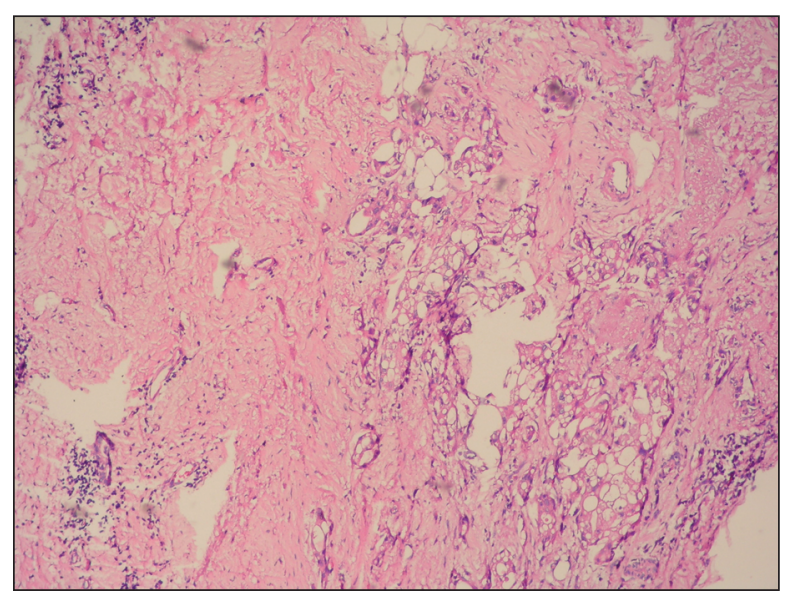

Figure 3. Histology showing invasive apocrine carcinoma of the breast - H\&E, (x100).

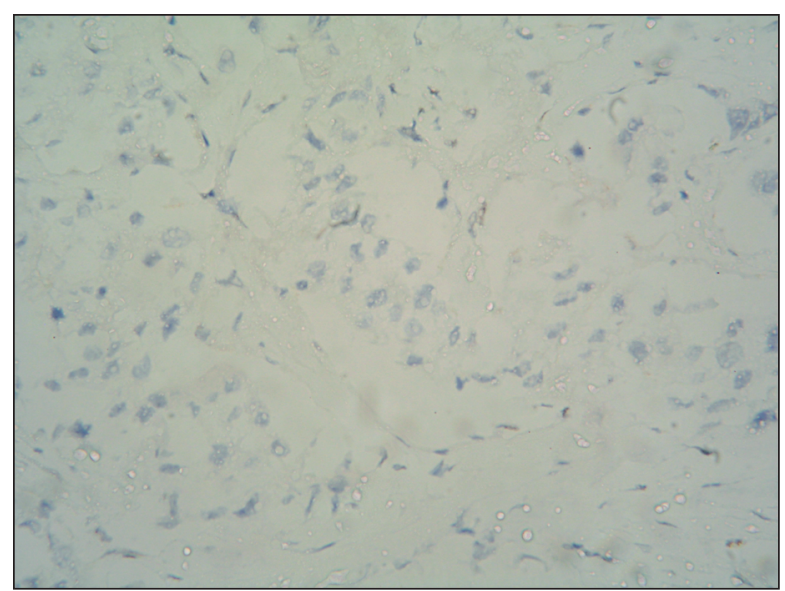

Figure 5. The apocrine tumor cells, negative for ER receptor $-\mathrm{ICH},(\mathrm{x} 400)$.

with moderate pleomorphism and prominent nucleoli (Figure 3), and fields of high grade apocrine ductal carcinoma in situ (DCIS) (Figure 4). There was no lymphovascular invasion. The immunohistochemical

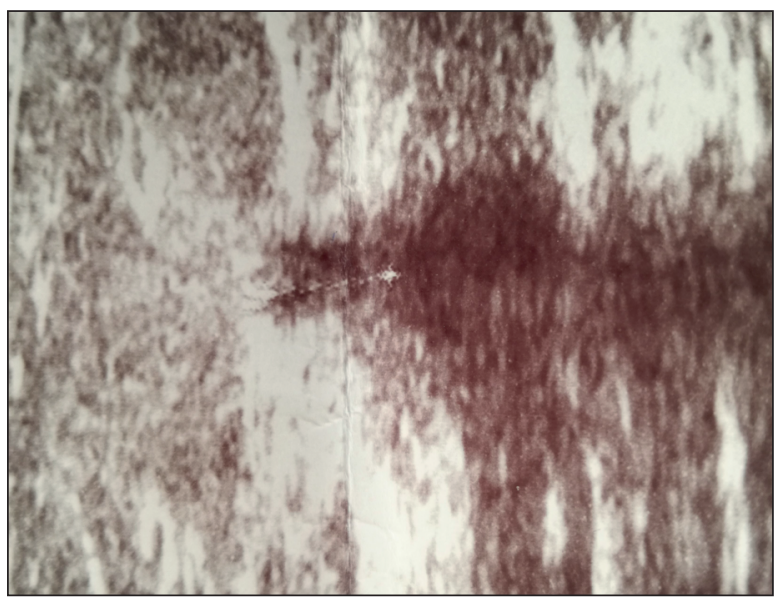

Figure 2. Ultrasonography revealing a $5 \mathrm{~mm}$ hypoechoic lesion in the upper inner quadrant of the right breast.

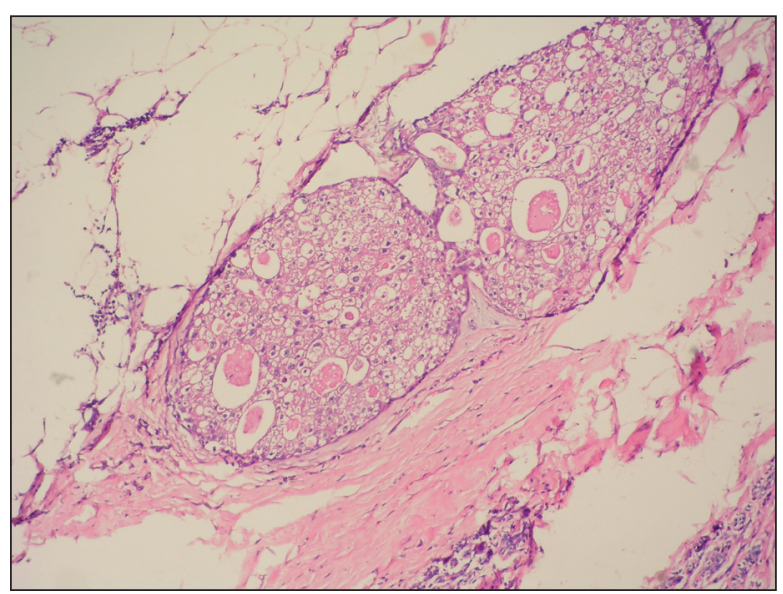

Figure 4. Apocrine ductal carcinoma in situ $\mathrm{H} \& \mathrm{E},(\mathrm{x} 100)$.

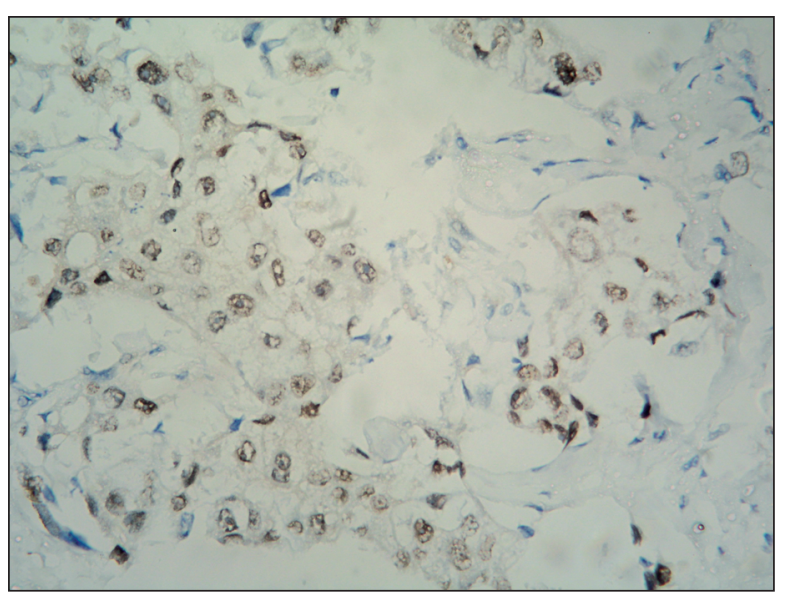

Figure 6. AR-positivity in about $80 \%$ of tumor nuclei - ICH, (x400).

study of the tumour population showed a negative reaction for ER and PR receptors (Figure 5), nuclear positivity in more than $80 \%$ of tumor cells for AR receptor (Figure 6), focal immunoexpression for 


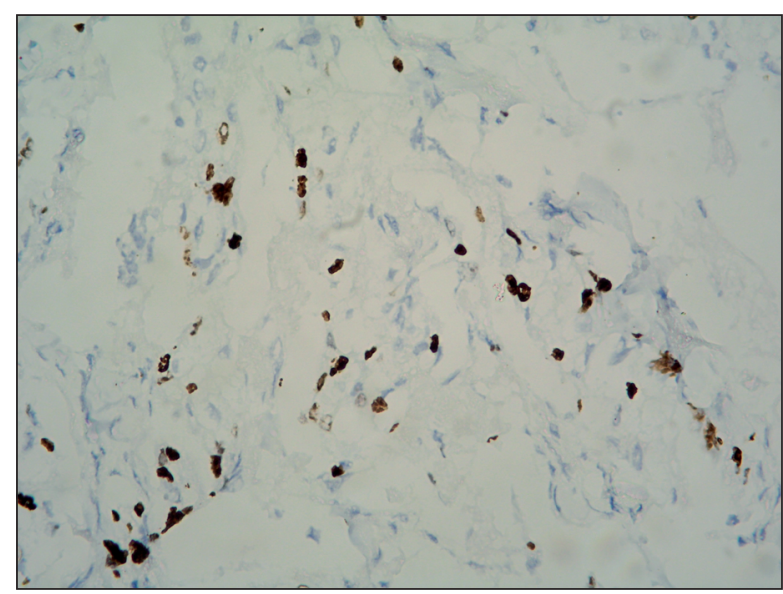

Figure 7. Ki-67 labelling index was found to be $30.1 \%$ (hot spot) $-\mathrm{ICH},(\mathrm{x} 400)$.

GCDFP-15, HER2 (1+) and negative reaction by chromogenic in situ hybridization method. The proliferative marker Ki-67 nuclear staining was 30.1\% (Figure 7). According to the modified Bloom and Richardson scale, the histologic grading was determined as Grade 2 [score $7(3+3+1)$ ]. The SLN was examined in 28 steps over 60 micrometers, with a micrometastasis, the largest diameter of $1.35 \mathrm{~mm}$ being detected from $23^{\text {rd }}$ to $27^{\text {th }}$ steps (Figure 8 ).

Because of the involvement of one of the resection lines from high grade apocrine DCIS, a modified radical mastectomy with axillary dissection was performed. The final diagnosis was IAC-G2, pT1aSLN1micM0, St.1B/ II. By decision of the Oncology Committee, the patient was recommended adjuvant systemic chemotherapy with weekly Paclitaxel 80 $\mathrm{mg} / \mathrm{m}^{2}$ (twelve courses), hormonal anti-AR therapy with Bicalutamide accord $50 \mathrm{mg} /$ daily (for 3 years), and molecular genetic analysis for BRCA1/2, which didn't detect pathogenic variants. The control examinations with positron emission tomography scan, mammography of the contralateral breast and axilla, and tumour markers over a two-year period did not show disease progression.

\section{Discussion}

Malignant apocrine lesions of the breast (non-invasive and invasive) belong to the rare histological subtypes of mammary carcinomas. The incidence of IAC of the breast in the various reports varies from $0.4-15 \%$ \% 13,5 . Gogoi et al reported the lowest incidence, $0.3-1 \%$ of breast cancers, and included them in the group of "relatively rare carcinomas" ${ }^{\text {". }}$. The differences in the frequency of IAC of the breast are due to differences in the morphological criteria for its determination, as well to being less often studied. The IAC

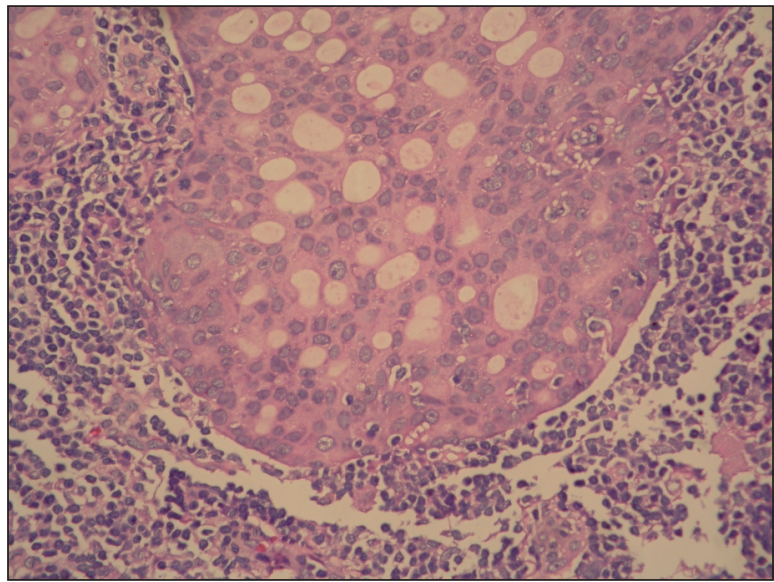

Figure 8. SLN with micrometastasis of apocrine carcinoma-H\&E, (x400).

of the breast is a neoplasia composed, in $80-90 \%$, of two types of tumour cells based on the cytoplasmic features. The first type is with abundant eosinophilic granular cytoplasm (periodic acid-Schiff +), oval nuclei and prominent nucleoli (type A cells), and the second type is with abundant foamy cytoplasm and lipid intracytoplasmic inclusions (type B cells)? ${ }^{7}$. Tumours with less than $80 \%$ of the cells with apocrine cytological features are considered invasive ductal carcinoma with apocrine features ${ }^{7,8}$. In 2005, Japaze et al standardized the criteria for IAC of the breast: 1) $75 \%$ of tumor cells have apocrine characteristics; 2 ) large cells with eosinophilic granular cytoplasm; 3) nucleus/cytoplasm ratio $1: 2$ or more; 4) large oval or pleomorphic vesicular nuclei; 5) sharp distinct cell boundaries ${ }^{3,7}$. Optional (minor) criteria include: prominent nucleoli greater than $50 \%$ of the field and apical snouts into luminal spaces ${ }^{3,7}$. Our case fulfilled all five criteria. Apocrine carcinomas of the breast are more common variants of invasive ductal carcinoma, while invasive lobular carcinomas are less likely to show apocrine differentiation. No clinical differences were found between IAC of the breast and invasive ductal carcinoma of no special type. They are presented as a matter of different sizes, irregular shape, without predilection and skin involvement. According to some authors, they are more often localized in the right breast, as in our case ${ }^{7,8}$. There may be multifocal and/or multicentric spread and risk of developing cancer in the contralateral breast ${ }^{8,9}$. IAC of the breast occurs in women between 60-70 years of age and it is extremely rare in men ${ }^{8,9}$. The mean age is 57.1 years, but in the study by Kiyici et al, the mean age was 53.9 years, which is closer to the age of our patient ${ }^{5,7,10}$. The IAC of the breast shows a low incidence of axillary lymph node metastases (1-4\%) and lymphatic invasion compared to invasive ductal 
carcinoma of no special type, which is associated with better prognosis and favorable clinical behavior ${ }^{10,11}$. Isolated cases of axillary lymph node metastases have been described in the literature; however, our case is the first, to our knowledge, to be described with the presence of a micrometastasis in the SLN in a patient with rheumatoid arthritis ${ }^{12}$. Mammography and ultrasound examinations cannot classify IAC of the breast because radiological data do not differ from invasive ductal carcinoma of no special type. Macroscopically, the tumour is yellow-brown, with a prominent cut surface, and microscopically it has invasive growth and a structure similar to invasive ductal carcinoma of no special type, but with different cytological characteristics ${ }^{13,14}$. Histologically, tumour cells have eosinophilic cytoplasm, sharp borders, oval nuclei, and visible nucleoli. The IAC of the breast is graded similarly to invasive ductal carcinoma of no special type. Most of the IAC of the breast are G2-G3. According to some authors, the grading of IAC of the breast correlates with the loss of estrogen and progesterone receptors ${ }^{3,15}$. The mitotic activity of neoplastic cells in the IAC of the breast is moderate or high in the context of TNBC. Regarding the differential diagnosis, IAC of the breast should be distinguished from other special types, such as oncocytic carcinoma, secretory carcinoma, lipid-cell rich carcinoma, and histiocytoid carcinoma ${ }^{3,16}$. The IAC of the breast is associated with an apocrine in situ component, as observed in our case. The association with benign lesions is not well understood, but apocrine adenosis, metaplasia, and hyperplasia may have premalignant potentia ${ }^{17,18}$. Immunohistochemical analysis of the IAC of the breast shows that it has a unique profile, represented by negative receptor status for ER and PR, and according to Tanaka et al, these can be expressed in $16-25 \%^{1,17,18}$. AR receptor overexpression is a hallmark of IAC of the breast, which has a predictive role for hormonal therapy, and, in the subgroup of ER-negative patients, was considered a good prognostic factor ${ }^{15}$. Other markers for apocrine differentiation are GCDFP-15, 5-alphareductase (expressed in 60\%), gamma-glutamyl transferase, tumour-associated glycoprotein ${ }^{2,3,17}$. GCDFP-15 expression in IAC of the breast correlates with small size, negative lymph nodes, and low grading, which is not confirmed by our case ${ }^{2}$. HER2 in the IAC of the breast in $50 \%$ shows a negative reaction, which places it in the category of TNBCs $s^{4,17,18}$. By molecular characteristics, the IAC of the breast belongs to the "molecular apocrine group". Studies show that apocrine tumours are different from the luminal and basal-like subtype of mammary carcinomas, because they are characterized by increased AR signals along with HER2 gene signals ${ }^{14,16,17}$. In a review by Vranic et al, the triple-negative apocrine carcinoma of the breast is subdivided into 2 apocrine groups: apocrine basal gene group and apocrine luminal gene group ${ }^{18}$. Modified radical mastectomy, chemotherapy and hormonal therapy are considered the standard treatment for patients with IAC. Information on the response to neoadjuvant chemotherapy is limited, with some studies reporting a pathological response to neoadjuvant chemotherapy in about $30-50 \%$ of apocrine carcinomas ${ }^{8}$. Experimental data indicate that TNBCs with AR overexpression may be sensitive to AR-antagonists (Bicalutamide) and have a complete therapeutic response $\mathrm{e}^{18,19}$. In the past, methotrexate has been used therapeutically as an anti-cancer drug in breast cancer, and it is also used as an immunosuppressant in the treatment of rheumatoid arthritis, in doses one-tenth or one-twentieth of the dose in the treatment of mammary carcinoma, as reported by our case. Studies show that the risk of developing breast cancer in patients with rheumatoid arthritis who are treated with methotrexate is not higher compared to that in healthy individuals ${ }^{20}$.

The prognosis of patients with IAC of the breast is unknown, due to the small percentage of cases and incorrectly applied diagnostic criteria. Some authors identified better overall survival and breast cancer-specific survival for patients with $\mathrm{AR}(+)$ apocrine triple-negative carcinomas (over 6 years in $72 \%$ ) compared with invasive ductal carcinoma of no special type $(52 \%)^{11,19,21}$.

\section{Conclusions}

Apocrine carcinoma is a rare specific morphological type of invasive breast cancer. It is a real morphological challenge that requires an immunohistochemical panel to prove its apocrine nature and distinguish it from other types of breast cancer. The unique immunohistochemical profile, the possibility of an anti-AR therapy, and the favorable prognosis separate it from the basal-like TNBCs.

\section{Author Contributions:}

T.B. and I.I. made the histopathological diagnosis. S.P. made the immunohistochemical analysis and consulted the histopathological diagnosis. S.K. - consultant of ethical issues of the article. T.B. and R.T. wrote the manuscript. All authors have read and agreed to the published version of the manuscript.

\section{Compliance with Ethics Requirements:}

"The authors declare no conflict of interest regarding this article" 
„The authors declare that all the procedures and experiments of this study respect the ethical standards in the Helsinki Declaration of 1975, as revised in 2008(5), as well as the national law. Informed consent was obtained from the patient included in the study"

"No funding for this study"

\section{Acknowledgements:}

None

\section{References}

1. Tanaka K, Imoto S, Wada N, Sakemura N, Hasebe K. Invasive apocrine carcinoma of the breast: clinicopathologic features of 57 patients. The Breast Journal 2008;14(2):164168.

2. Kim JM, Kim SY, Oh MH, Lee JE. A rare case of invasive apocrine carcinoma of the breast with unusual radiologic findings. Iranian Journal of Radiology 2016;13(3):e35298.

3. Shinde BB, Chandak AJ, Giriji DD, Sonwane SR. Apocrine carcinoma of breast: a rare case report. International Journal of Clinical and Biomedical Research 2015;1(1):22-24.

4. Arce-Salinas C, Riesco-Martinez MC, Hanna W, Bedard P, Warner E. Complete response of metastatic androgen receptor-positive breast cancer to bicalutamide: case report and review of the Literature. Journal of Clinical Oncology 2016;34(4):e21-e24.

5. Kiyici H, Guler G, Altundag K. Carcinomas with apocrine differentiation: comparison of clinicopathologic features with invasive breast carcinoma of no special type (NST) in Turkish patients. International Journal of Hematology and Oncology 2014;24(2):118-122.

6. Gogoi G, Borgohain M, Borah A, Agarwal V. Study on apocrine carcinoma of breast: histomorphologic features and immunohistochemical behavior. International Journal of Basic and Applied Medical Sciences 2012;2(3):190-193.

7. Muthusamy RK, Mehta SS. Giant apocrine carcinoma of the breast: A case report with review. Asian Journal of Oncology 2018;4:21-24.

8. Yee C, Wan BA, Drost L, et al. Apocrine carcinoma of the male breast: a case report. Annuals of Breast Cancer and Therapy 2017;1(1):12-14.

9. Gutesa I, Roth A, Milas I, et al. Rare breast tumors. Libri Oncologici 2014;42:75-81.
10. Khandeparkar SS, Deshmukh SD, Bhayekar PD. A rare case of apocrine carcinoma of the breast: cytopathological and immunohistopathological study. Journal of Cytology 2014;31:96-98.

11. Wader JV, Saini S, Kumbhar SS, Saini N. Apocrine carcinoma of breast: specific histopathological subtype. International Journal of Healthcare and Biomedical Research 2015;3(4):51-54.

12. Bedford T, Alperstein A, Nathani Y, Marx R, DeVito P. A rare presentation of triple-negative apocrine breast carcinoma with metastases. Journal of Surgical Case Reports 2014;5. doi:10.1093/jscr/rju045

13. Tsutsumi Y. Apocrine carcinoma as triple-negative breast cancer: novel definition of apocrine-type carcinoma as estrogen/progesterone receptor-negative and androgen receptor-positive invasive ductal carcinoma. Japanese Journal of Clinical Oncology 2012;42(5):375-386.

14. Vranic S, Feldman R, Gatalica Z. Apocrine carcinoma of the breast: A brief update on the molecular features and targetable biomarkers. Bosnian Journal of Basic Medical Sciences 2017;17(1):9-11.

15. Agrawal A, Ziolkowski P, Grzebieniak Z, Jelen M, Bobinski $\mathrm{P}$, Agrawal S. Expression of androgen receptor in estrogen receptor-positive breast cancer. Applied Immunohistochemistry E Molecular Morphology 2016;24:550-555.

16. Arif SH, Haider N, Ansari HA, Rehman S, Raza MH. Pure invasive apocrine carcinoma of the breast: a rare entity. Middle East Journal of Cancer 2013;4(3):131-133.

17. Wader JV, Jain A, Bhosale SJ, Chougale PG, Kumbhar SS. Apocrine carcinoma of breast: a case report with review of the literature. Case Reports in Pathology 2013;2013:170918.

18. Vranic S, Schmitt F, Sapino A, et al. Apocrine carcinoma of the breast: a comprehensive review. Histology and Histopathology 2013;28:1393-1409.

19. Zhang1 N, Zhang1 H, Chen1 T, Yang Q. Dose invasive apocrine adenocarcinoma has worse prognosis than invasive ductal carcinoma of breast: evidence from SEER database. Oncotarget 2017;8(15):24579-24592.

20. Kumaki N, Okamatsu C, Tokuda Y, Nakamura N. Breast cancer in patients of rheumatoid arthritis with methotrexate therapy mimicking histopathological changes after neoadjuvant chemotherapy. The Tokai Journal of Experimental and Clinical Medicine 2017;42(2):104-108.

21. Provenzano E, Gatalica Z, Vranic S. Epithelial tumors of the breast, WHO Classification of Tumours Editorial Board, WHO Classification of Tumours 5th Edition Breast Tumours, Lyon (France): International Agency for Research on Cancer 2019:131-133. 